\title{
Failure of I-statements for Mitigating Interpersonal Conflict in Arguments Between Young Adult Couples
}

\author{
Neill Korobov \\ Correspondence: Neill Korobov, University of West Georgia, United States. \\ Received: Aug. 27, 2020 \\ doi:10.11114/smc.v8i2.4982 \\ Accepted: Oct. 6, 2020 \\ Online Published: Nov. 12, 2020 \\ URL: https://doi.org/10.11114/smc.v8i2.4982
}

\begin{abstract}
This study examines how young adult romantic couples use I-language (talk about one's own feelings or thoughts) in arguments that emerge in the couple's natural contexts. A discourse analytic approach is used to examine how I-language is used in conflict among young adult intimates. Focus is given to the role that evaluations and assessments play in managing talk about one's feelings during arguments. One of the central findings is that arguments tend to be intiated with I-language feelings talk. However, rather than stymieing conflict, I-language use was met with deflection that utilized objective rejoinders. However, when I-language was built not simply as a way of showing how one felt, but rather to show an awareness of the other's feelings or the overall dynamic in general (a kind of meta-subjective awareness), Ilanguage did tend to promote alignment and/or affiliation. This study thus offers a helpful window into not only the lived everyday texture of young adult couples argumentative interactions, but also a micro-analytic look at how those interactions both falter and at times succeed in circumventing conflict.
\end{abstract}

Keywords: I-language, Discourse Analysis, romantic relationships, feeling-talk, arguments, conflict

\section{Introduction}

One of the historically accepted dictums within the lore of interpersonal communication is that the use of 'I-language' (talking about your own feelings/perspectives) as opposed to 'you-language', particularly during conflict among romantic intimates, is less likely to result in negative emotions and more likely to lead to cooperation from the recipient (Bieson, Schooler \& Smith, 2016; Kidder, 2017; Kubany, Richard, Bauer, \& Muraoka, 1992, 1995a, 1995b; Rogers, Howieson, \& Neame, 2018). The popularity of I-statements as a conflict resolution device is longstanding and was originally broached by the American psychologist Thomas Gordon (1970) who coined the term 'I messages', which was an extension of Carl Rogers' (1951) encouragement of couples to take responsibility for their own feelings by using I-statements to communicate with one another.

The justification for this within interpersonal communication research derives mostly from attribution theory (see Ross, 1977), which argues that taking ownership for one's emotions and feelings tends to predict positive reactions in recipients. To the extent that people take responsibility (i.e., an internal attribution) for their negative feelings (rather than blaming the other), they are more likely to be heard by their partner. In contrast, attribution theory predicts that when speakers blame their partners for their negative feelings (i.e., make an external attribution), an inhospitable reaction is likely. Over the last half century, the use of I-statements to communicate one's feelings and mitigate conflict has thus been widely encouraged across both academic and self-help psychological literature (see Bieson, Schooler \& Smith, 2016; Bloomquist, 2012; Bruneau \& Saxe, 2012; Hargie, 2011; Heydenberk \& Heydenberk, 2007; Kidder, 2017; Moore, 2014; Rogers, Howieson, \& Neame, 2018; Simmons, Gordon \& Chambless 2005; Whitcomb \& Whitcomb, 2013).

Despite its longstanding popularity, research promoting the use of I-statements in conflict management is surprisingly weak and derives mostly from anecdotal therapeutic observations or detached experimental mockups that utilize hypothetical scenarios. And in some cases, the findings have been counterintuitive. For example, interventional research (e.g., Jacobson et. al., 1984) has found that while the trained use of I-statements often lead to a decrease in negative interactions over the short term, they did not predict an increase in positive interaction, and that couples often reported quickly relapsing back into the use of You-language with accompanying levels of conflict. In Joanna Wolfe and Elizabeth Powell's (2009) qualitative work on female engineers' conversations, they surprisingly found that 'I-feel' statements were often ineffective and counter-productive, even backfiring at times.

This coincides with contemporary research that has argued that focusing on one's own feelings can make a person 
vulnerable and open to having their perspectives refuted rather than accepted (Nosko, Wood, \& Molema, 2010; Weisbuch, Ivcevic, \& Ambady, 2009). This may be particularly true for young adults situated within present-day 'selfie' culture. In the present world of hyper-digitally mediated youth interpersonal communication, the ubiquity of social media exacerbates the press to constantly share what one thinks and feels, which may at times seem off-putting or even narcissistic, thus inviting resistance. It is possible this resistance may affect the way focusing on one's own feelings comes across, especially when disagreement lurks. In short, the empirical research on the use and effectiveness of I- versus Youstatements during interpersonal conflict is not straightforward and has rarely been studied in actual everyday live interactions, especially between young adult romantic partners in contemporary interactional contexts.

The present study focuses on the use of I-language (talk about one's own feelings) in arguments between young adult romantic intimates in their everyday lived contexts. Extant research on the arguments between romantic couples focuses mostly on the effects of negative communication styles during couple's arguments (see Argyle \& Furman 1983; Cramer 2001; Estrada 2012; Gottman \& Levenson 2002; Trapp \& Hoff 1985). Though useful in certain contexts, this arena of research rarely examines the spontaneous occurrence of the couple's arguments as they emerge in real time. The arguments are often collected via self-reports or from interviews. Consequently, we know very little about how couples manage everyday arguments as they spontaneously emerge, in real time, as part of the social business of everyday interactions. And we know even less about how the press to focus on oneself in 'selfie' culture may impact the effectiveness of Ilanguage in managing conflict.

Although there is a wide range of research foci when it comes to arguments, this study focuses specifically on what happenes when young adult romantic couples use I-language (talk about their own feelings) to formulate what could be heard as a criticism or complaint about their partner during arguments. It is possible that the when speakers use I-language to refer to their own feelings about something potentially contentious, it will disarm their partner and stymie conflict and enhance positive communication. This would be in keeping with the historically popular understanding and recommendation for the use of I-language. However, it is also possible that in contemporary young adult culture Ilanguage is not as neat and tidy as one might expect, and that it's use will serve at times as a preliminary for various types of counters or resistance. This study aims to serve as an initial foray into understanding this phenomena.

\section{A Discursive Psychological Approach}

A Discursive Psychological approach is the method used in this study to analyze the ways young adult romantic partners use feelings (or I-language) in arguments. Discursive psychology (DP) focuses on analytically rich and descriptive accounts of human subjectivity (Edwards, 1997, 2007; Edwards \& Potter, 2017; Potter, 1996, 2003). DP approaches subjectivity not through self-report, but by examining how people make relevant their own and other's dispositions, feelings, and often mental states while building assessments and descriptions of things. With respect to arguments, speakers will often reference to their own 'feelings', the feelings of the other, about what happened or should have happened (see Edwards, 1995). Discursive Psychology does not treat these feelings as reflections of an inner psychological/mental world, but rather treats them as social and interactional resources that speakers use to tend to the business of relationships. In addition, feelings talk often rhetorically manages accountability or blame (Edwards, 1995, 1999).

A DP approach is rhetorically sensitive in that it attempts to identify the argumentative organization of talk (Billig, 1987). This entails a close look at how talk is built to work up versions of reality that often present contradictory and inconsistent versions of people, states of mind, motives, and events (Billig, 1987). Potter (1996) notes that there is an 'offensive' and 'defensive' rhetorical nature to the ways assessments and descriptions are built in talk, an idea consonant for a DP examination of arguments. Rhetoric works offensively in so far as it undermines alternative positions and it works defensively in so far as it has the capacity to resist or deflect potential challenges or counters. Since talk that involves criticisms is delicate, it will likely encompasses a variety of rhetorical functions (both offensively and defensively) to make claims that are not easily countered.

Additionally, the present study involves moments of heated arguments, where feelings are being used by speakers to make assessments of both what they are feeling and what their partners are purportedly doing (see Edwards \& Potter, 2017). As such, the kind of interactional work brought off during argumentative exchanges is clearly a matter of accountability (see Edwards, 1995; Edwards \& Potter, 1992), e.g., delivering and deflecting blame, constructing veracity, owning epistemic rights, as well as handling the sensitive issues surrounding being liked/loved by one's partner. Accountability in DP highlights the ways versions of events are constructed to imply responsibility. That is, when versions or descriptions are offered, they are done so in specific ways that attend to the often delicate issues of blame and mitigation (Edwards, 1995; Edwards \& Potter, 1992). In DP, attention is given to the ways speakers assign (or deflect) responsibility, meaning that descriptions of events are generally likely to have at the very least an inferential relationship to the actions and agency of the speaker. 
Consonant for a DP study on how feelings-talk works in arguments, Edwards and Potter (2017) make a useful distinction between subject-side (S-side) and object-side (O-side) assessments (see also, Pomerantz, 1984). O-side assessments are generally more prevalent in natural conversations. They carry epistemic weight or priority because they are constructed as being true independent of the speaker (see Heritage \& Raymond, 2005). They are often useful for delivering compliments as they do not restrict the judgment to the speaker (Wiggins \& Potter, 2003). S-side assessments (e.g., Ilanguage positions) are generally useful for talking about one's feelings - for restricting the judgment to the speaker, for showing that one has the relevant experience to enable an assessment, and for delivering a negative assessment without offending the other. S-sides are also good for avoiding offense, misalignment, and for generally managing interactional sensitivities, which squares with the historical preference for I-language. They often enable disagreement without contradiction; one can define differences as a matter of subjective preference or taste (see Edwards \& Potter, 2017). They are also good for doing compliment receipts (Wiggins \& Potter, 2003). The following analyses will look specifically at the use of S-sides and $\mathrm{O}$-sides to manage I-language in arguments between young adult romantic partners.

\section{Data}

The current project is part of a larger series of studies interested in intimacy, identity, and romantic attraction in emerging adults (see Korobov, 2011a, 2011b, 2017, 2018, 2020; Korobov \& Laplante, 2013). Young adult couples (ages 19-26) were recruited from a large university in the Southeast USA through word of mouth, posters, and emails. To be eligible to participate, all couples had to report being in a committed romantic relationship for at least 6 months. Though we were open to both heterosexual and homosexual couples, all the couples that agreed to participate were heterosexual. The resulting participant pool was thus comprised of 20 heterosexual romantic couples from the university and the local community. The study received IRB approval. Proper ethical guidelines were followed, including the provision of pseudonyms for all participants.

The aim was to procure data from natural settings rather than researcher moderated interviews or questionnaires. Participants were told that they would be participating in a study interested in the conversations that take place between young adult couples in the spaces of their everyday home-lives. Each couple was given a digital audio recorder to take home for 2 weeks with the instruction to simply turn the recorder on whenever they were hanging out (i.e., eating meals, driving in the car, taking a walk, cuddling, watching TV, cooking, etc). At the end of the two weeks, the digital recorders were returned, and the participants were paid $\$ 25$. In sum, each couple produced an average of approximately 7 hours of recorded conversational interaction, for a total of approximately 140 hours of conversational data.

Although the conversations took place in the couple's natural everyday settings, the participants did have to self-select about when to turn the audio recorders on and tend to them somewhat. That said, the participants rarely oriented to or made mention of the audio recorders, nor did any participants self-censor or display discomfort about being recorded. Their conversations had a very natural rhythm and feel to them, which is not surprising given the fact that young adults are now, more than ever, thought of as an increasingly confessional generation of young adults accustomed to performing their identities across an array of social media outlets (see Nosko, Wood, \& Molema 2010). Social scientists have further noted that arguments and verbal tiffs, as well as the types of critique-and-response patterns evidenced in this data set, are normalized as parts of candid self-presentation and that now, more than ever, it may be trendy to be candid-i.e., edgy, real, and provocative (Chiou 2006; Weisbuch, Ivcevic, \& Ambady 2009; Valkenburg \& Peter 2009). As such, the natural interactional contexts used in this study, as well as this developmental age of young adulthood, may be apropos for capturing argumentative moments rife with feelings talk.

The data presented here is a subset of a wider study examining the conversations between young adult romantic partners. This study focuses on the ways couples argue, specifically examining the use of I-language, or feelings (vis-à-vis S-side and $\mathrm{O}$-side assessments). Analysis thus focuses on argumentative exchanges. One key finding that drives the present focus was that many (over 61\%) of the arguments contained moments where one speaker would deflect a contentious or critical I-language type position back on to her/his partner. These moments are the focus for the current analyses below. A light version of Jefferson's (2004) transcription conventions (see Appendix 1) is used, which is standard for DP.

\section{Analysis}

The following analyses are parsed according to the most common forms of receipt for the use of I-language (S-sides) in the couple's arguments. The most prevalent response to the use of one's own feelings (S-sides) to initiate and manage conflict was deflection by using O-side rejoinders. In excerpt 1, Dee says that she is hurt because she feels she is not enough for Earl. Note Earl's O-side deflections. 


\subsection{The use of O-sides to Deflect the I-language of S-side Feelings Talk}

\section{Excerpt 1}

DE 3 (112:04)

1 Dee: you know I hate doin'this with'u (.) I'm

2 hurt (.) feel like I'm not enough sometimes.

3 Erl: babe you bring that on yourself (.) that's you.

4 Dee: ughh: (.) wow (.) so I'm jus' left like that (.)

$5 \quad$ like this is how I feel Earl (.) damn.

5 Erl: it IS: kinda on you (.) ya know (.) that's what

you gotta deal with I guess (.) take a look at

7 yourself I dunno (.) but don't put it on me.

Dee uses I-language to note that she feels like she is not enough for her boyfriend. She marks the delicacy of such confessions by saying she hates doing this with him. She uses a S-side (I'm hurt I feel) to mark that her feelings about what Earl is doing are her own, which may stymie a negative response. Such opening S-sides were common this data set. Note, however, how Earl responds in line 3. He uses an objective O-side to quickly flips it back on Dee by claiming that she brings that on herself. He situates the blame on her, which is not suprising given that this is an argument launched by Dee's I-language S-side. In arguments, I-language can often be heard as other-implicative (see Edwards \& Potter, 2017). Talk about one's own feelings has an inferential quality at times. The listener may infer that they are somehow being blamed or critqued.

What is evident here is the ways O-sides are useful for handling the lurking blame that is hearable in I-language forays into relational critiques. In line 4, Dee continues to emphasize her own feelings using I-language, even claiming epistemic privilege for her stance. Earl cannot, after all, deny that she feels the way she feels. However, he orient once again to her S-side with another O-side deflection, which he does in lines 5-7. He once again emphasizes that her hurt is her own problem that she must deal with. What is clear here is the way the subject-side construction inherent in I-language is met with O-side resistance/deflection, and how these alternating constructions can unfold in the space of a burgeoning argument. In this next excerpt, Adi insinuates that her boyfriend Zane can be possessive.

\section{Excerpt 2}

ZA 5 (55:34)

1 Adi: it came up in the car (.) on way to practice

2 (.) they just raggin' on Marc and Holly haaha::

3 cause she's up in his biz way much n'I was all::

4 uhh:: I feel that (.) I can relate=

$5 \quad$ Zan: $=$ why?

6 Adi: cuz: (.) I feel like (.) like how Marc feels.

7 Zan: nah fuck that (.) you are so wrong.

8 Adi: well I feel like you do kinda pry.

9 Zan: there might be a good reason for that.

10 Adi: that's weak man (.) I know who I am.

11 Zan: do you? yeah Adi (.) you can be sketchy.

12 Adi: whatever.

The excerpt opens with Adi referencing a recent conversation she had with mutual friends where they were 'raggin' on their friend Holly for being too controlling on her boyfriend Marc. Using laughter as levity as well as hedges and displays of uncertainty, Adi delicately uses subject-side I-language to note that she can relate to Marc. She grounds her assessment and potential critique in her own perspective. In a way that parallels the first excerpt, Zane (line 7) counters with a strong O-side retort ("you are so wrong") that dismisses her comparison and, by extension, the potential critique of him as controlling. In line 8, Adi again delicately uses the subjective-side I-language to say that she feels he does 'kinda pry'. 
Following this turn, Zane ups the ante and uses strong O-side rejoinders to move from resistance to deflection. In line 9 , he notes that 'there might be a good reason for that', which is an interesting move. It to some degree accepts the potential veracity of her claim that he does in fact pry, which lends some weight to the power of her S-side construction of her own feelings. However, instead of owning it or accepting blame for her feelings, he deflects it. She attempts to intercept the deflection in line 10 with an O-side/S-side combination move ("that's weak man"/'I know who I am"). Again, the S-side works as a preliminary for another O-side response from Zane, who counters back in line 11 to first cast doubt ("do you?") on her I-language construction, and then another strong O-side rejoinder in noting that Adi can be sketchy, which situates the blame on her for his prying behavior.

What is common across both except 1 and 2 is the oscillating pattern between S-side and O-side constructions. The use of I-language to subjectively anchor and a critique does not seem to soften the recipient for hearing something that is potentially difficult. Instead, the recipient typically responds with O-side dominant deflection. We can also see how Oside deflections build as the I-language of S-sides become epistemically stronger. Curiously, we also see that those using I-language (Dee and Adi in the first two excerpts) could at any point counter back with O-sides but instead for the most part stick to using subjective I-language to ground their positions.

\subsection{The Use of S-side Feelings-Talk to Manage Other S-side Complaints}

At times, one speaker would orient to an I-language position with their own S-side constructions.

Excerpt 3

\section{YK 1 (5:25) Yael and Ken}

1 Ken: I waited up until like at least 11:30.

2 Yael:you ca:n call if ya don't hear from me.

3 Ken: I'eh: (.) yeah I felt that'd be weird.

4 Yael:I feel it'd uv'been kinda sweet to=

5 Ken: =harass you?

6 Yael:NO: (.) it's like gentleman (.) to me (.)

7 makes me feel like you're thinking of me.

8 Ken: I felt like if you were thinking of me that

9 you'd call (.) I was waiting up.

10 Yael:I didn't know n'besides I think it's weird=

11 Ken: =what is.

12 Yael:to be waiting up wanting to talk but not just

13 calling.

14 Ken: yeah to me that's normal to not.

15 Yael:I'm sensing like a macho thing.

16 Ken: nope (.) just I'm gonna go to bed (.) you

17 have my number if ya wanna talk.

18 Yael:ugh:: annoying.

Though not uncommon, this type of excerpt deviates from the most common pattern noted above. There is not the typical $\mathrm{S}$ - to O-side oscillation. There is also a dearth of O-sides in general. Instead, Ken and Yael use a cascade of consecutive S-sides (I-language) to manage their argument. The strong I-language begins in line 3 as Ken asserts that it would be weird for him to call his girlfriend when he is waiting up for her to call him. Yael feels it would be sweet (line 4) and a gentlemanly (line 6) sign that he was thinking of her (line 7); Ken feels it would be harassing (line 5). Not the way that no mutual agreement or shared perspective taking is achieved early on, even though both speakers are using exclusive Ilanguage to communicate their own feelings on the matter. Note the way Ken uses an S-side in line 8-9 to deflect her own desire for thoughtfulness back on her. It is here that we can see that S-sides can smuggle in the feel of an O-side deflection.

As the except continues, Yael parallels Ken's previous move and uses an I-language construction across lines 10 and then 12-13 in a curious way. Using 'I think', she builds a S-side that feels like an O-side, though it omits the you-language typical in an O-side. Rather than saying 'I think it's weird for you to wait up wanting to talk...', she speaks in the general voice and notes 'I think it's weird to be...', thus softening her assertion from appearing directed at him specifically. 
However, as evident in line 14, Ken takes it personally and responds with the I-language construction of 'yeah to me' in his rejection of Yael's implicit critique of him. Yael then retorts with another S-side in line 15 ("I'm sensing") that again implicitly criticizes Ken's resistance to reach out as a 'macho thing.' This S-side use of I-language once again has the feel of an O-side, though it is not explicitly built that way. The key take-away here is that even when I-language dominates in the form of consecutive S-side talk about one's own feelings, there is not necessarily agreement, cooperation, or affiliation, as the previous literature on I-language might predict. In fact, I-language can often have the feel on an O-side and can be oriented to as such.

This next section shows an example of what happens when consecutive O-sides dominate and the use of I-language is severely mitigated. Note the effect this has on intersubjective alignment, agreement, and cooperation.

\subsection{The Use of Consecutive O-sides (the Omission of I-language)}

Excerpt 4

HJ 3 (19:33)

1 Hen: Sean and Mike are always talkin' shit bout

2 Alyssa (.) basically that she gets in Chris'

3 head n'stuff (.) keeps him from them.

4 Jos: since when? (.) she seems cool t'me=

5 Hen: =hahha seriously (.) she's been like that

6 for months (.) started with the road trip.

7 Jos: that's cause those guys are jealous.

8 Hen: you defending her? (.) that's kinda ironic.

9 Jos: no:: not really and I'm not her so shut the

10 fugggh:: up (.) but no yeah=

11 Hen: it's so damn annoying (.) trust me.

12 Jos: you even seen it? (.) like first hand?

13 Hen: no but I don't need to.

14 Jos: you trust yo'boys wa::y to much.

15 Hen: you're naïve hhaha::.

16 Jos: maybe I dunno (.) jus glad we ain't like that.

17 Hen: seriously (.) I could not deal.

18 Jos: ohh:: you got it so:: good dontcha? hahah.

19 Hen: almost as good as youhahha.

20 Jos: ok now(hha) let's not be ridiculous.

This type of excerpt features a glut of initial O-sides in contrast to the more typical I-language openers that set off arguments. Common to these types of arguments is that the speakers are focused on external others (here, Henry starts by critiquing their mutual friend Alyssa for being controlling of her boyfriend Chris, as reported by their mutual friends Sean and Mike). Because they are building their brief tiff around others, it is not surprising that O-side assessments dominate the opening lines (through line 7). It is less personal (at first). However, in line 8, Henry positions Joss as potentially defending Alyssa's controlling behavior, which he cites as "ironic". His characterization of it as ironic is brought off with an O-side. She rejects his conjecture (lines 9-10) and playfully (using a derivation of the phrase 'shut the fuck up') reprimands Henry. Her terminal "but no yeah" is a re-indexing of her point in line 7 that jealousy on the part of Sean and Mike is at play here.

In line 11, Henry does not escalate her reproach, but rather uses another O-side to critique Alyssa's behavior ("it's so damn annoying). He does not go after Joss at all. Joss challenges his interpretation, and then uses an O-side to say that Henry trusts his male friend's interpretation too much. Henry counters with an O-side that positions Joss as naïve, but laughs as he delivers it, which softens it and casts it in a potential play frame. The excerpt ends by the two appreciating that they are glad that their relationship is not like this, and that they have it good by comparison. Several things are noteworthy here. The first is that O-sides are much more resilient when it comes to deflection. They seem less delicate. While S-side critiques are often flipped back and deflected, the O-sides here are not. Instead, there is a kind of tic-for-tat 
exchange that centers less on assigning blame than on exchanging critiques. Second, strings of O-side critiques are more likely to result in alignment, agreement, and affiliation. This is especially true when external others are part of the fodder in the argument. It's as if the O-side dominated gossip frame allows the speakers to pursue commonality more easily than would be the case if they used I-language to take personal positions vis-à-vis the other. This is an important finding that further undermines the bald claim that I-language may be most useful for finding commonality and affiliation. Here we see how consecutive O-sides create affiliation.

These last 3 excerpts are especially interesting. They feature a peculiar use of the subjective element of I-language and how it is created to not simply share one's feelings but instead to display a kind of meta-subjective awareness of the ways one's own issues may impact the other and thus contribute to the conflict.

\subsection{Using S-sides to Display a Meta-Subjective Awareness of the Other's Potential Feelings}

Excerpt 5

MN 4 (33:34)

1 Nat: we are only going for a few days (.) I

2 said that (.) you don't listen (.) n'

3 instead accuse me of forgetting which

4 I didn't.

5 Mic: but you do forget and don't listen (.)

6 often (.) so yeah I'm not jus'gonna like

7 forget that ok.

8 Nat: but I didn't this time.

9 Mic: yeah ok (.) I overreacted n' I do that=

10 Nat: =n'I feel set off.

11 Mic: I fe:el that (.) ok.

12 Nat: yeah:: I mean (.) ok (.) I can see (.)

13 yah I do forget some things (.) but I try

14 with the big stuff.

15 Mic: well my birthday is soon so ya better not

16 forget that(hhaa).

17 Nat: hha: what birthday hahha.

Nate opens with a double O-side ("you don't listen" and "accuse me of forgetting) critique. Michelle counters back with a general O-side dispositional scripting (see Edwards, 1994) of "you do forget and don't listen", which deflects his claim that she does not listen back on him. Nate then notes that he did not "this time", which is hearable as a concession that there is truth to her O-side scripting. This concession is important. It displays awareness of her position and sets a new trajectory for their argument. Michelle then agrees ("yeah ok") and then switches to a softer and more self-aware Ilanguage S-side in admitting that "I overreacted n' I do that"). The tone has shifted. Nate does not follow her S-side with a typical O-side deflection. Instead, he follows with the S-side I-language in acknowledging that he feels set off. Rather than respond with an O-side deflection to his S-side, Michelle responds with another self-aware use of I-language and appreciates ("I fe:el that") his sentiment. She displays acceptance and understanding of his position. Nate continues this (lines 12-14) building of intersubjective awareness with more I-language to display extended awareness of his girlfriend's experience of his forgetfulness. By the end of the excerpt, they are playfully joking about upcoming birthdays. What we see here is a new use of I-language to claim a different kind of subjective stance that is less about one's own perspective and more about an awareness of both perspectives.

Consider the next excerpt between Lou and Val arguing about Val's phone behavior that features a similar pattern.

Excerpt 6

LV $4(14: 22)$ 
1 Lou: oh now don't pick on Seth cuz we'both

2 know you do that (.) a lot.

3 Val: ok first all of ain't the same (.)

4 like (.) for real=

5 Lou: = I'm YEAH you jus' let it ring (.)

$6 \quad$ like flip it to silent (.) don't pick up

7 (.) looks shady as fuck.

$8 \quad(1.0)$

9 Lou: n' I know I like look like a lil' bitch=

10 Val: =hahhahha I was bout ta'say.

11 Lou: okay okay but I'm jus sayin'.

12 Val: hey look (.) okay (.) you ain't a bitch n'

13 I am NOT trying to hide anything or look

14 sketchy n' I know I do.

15 Lou: ok.

16 Val: I'll stop that (.) no problem (.) no need

17 to make ya feel any way bout it.

18 Lou: thank you baby.

19 Val: it's all good babes I gotchu (.) I feel ya.

Similar to the previous excerpt, there is a similar pattern, then in lines 5-14 Lou inserts an O-side "looks shady as fuck" (line 7), which after a slight pause, he softens to a more self-reflective and other-oriented S-sides in line 9, saying "I know I like look like a lil' bitch". This is another peculiar S-side that is less about Lou's feelings per se than it is about his awareness of how his actions look to his partner. Notice Val's receipt is not an O-side deflection, but is a laughter plus knowing S-side agreement. In what follows, Val defends Lou ('you ain't a bitch') an then herself uses an S-side in a similar other-oriented fashion to admit she knows she looks sketchy. As the excerpt plays out, the two use these unique other-oriented I-language S-side constructions to coordinate a shared perspective, take personal responsibility for the parts they each play in the conflict, and then affectively affiliate with one another by the end of the exchange.

This final excerpt between Aly and Dan arguing about Dan being perpetually late features this same pattern.

\section{Excerpt 7}

AD 2 (25:12)

1 Aly: ok so what time? is it 6 or $6: 15$ or?

2 Dan: I said 6 so that $=$

3 Aly: =yeah but 6 ends up being 6:15 or 6:30.

4 Dan: are you being serious (.) my god Aly.

5 Aly: yeah you aren't reliable (.) you just

6 do whatcha want half the time.

7 Dan:wow.

8 Aly: you don't watch your pho=

9 Dan: =exactly no I don't obsess bout time=

10 Aly: =right (.) I get it (.) you are in the

11 moment (.) it's outta your control when

12 you get to leave.

13 Dan: yes (.) you think I like letting you down?

I hate it (.) n' I know I do. 
14 Aly: it's fine (.) I know you intend well.

15 Dan: yes (.) n'trust I know you don't like waiting

around for me (.) I know that blows.

16 Aly: yes it's tough.

The S-O oscillating pattern begins across lines 10-12 as Aly constructs an other-oriented S-O combination as she opens with the "I get it" S-side then follows it with two O-sides about Dan being in the moment and not being able to control when he leaves. She effectively communicates understanding about who he is and his situation. As expected, this solicits alignment from Dan who agrees with her perspective and then a S-side acknowledgment that he knows he is letting her down and does not like it. Like in the previous two excerpts, this use of S-sides to project awareness of the other's perspective leads to both an aligning of perspectives on the situation as well as affective affiliation. Though these unique moments of other-oriented S-sides were not nearly as prevalent in this corpus as the more self-focused variety of S-sides, they reveal a very telling and important contrast that warrants further examination.

\section{Discussion}

The goal of this study has been to explore how young adult couples use I-language (references to their own feelings or thoughts) to handle the delicacy of argumentative exchanges in their natural contexts. Because I-language draws exclusively on S-sides (subjective assessments/evaluations), a discursive approach was utilized because of its microanalytic ability to examine both the subjective and objective nature of assessments and descriptions of people's dispositions and action as well as events in the world. Each type of assessment offers a unique type of epistemic weight for constructing positions that involve accountability in moments of argumentative exchange. The hope was to find out if patterns existed with the ways I-language drew on $\mathrm{S}$ - and O-sides.

A key finding is that most of the arguments were initiated with the unique features of S-side I-language and were often formulated in ways that tended to the delicate nature of the making a critique during conflict. The rhetorical weight of the critique was grounded in the lived experience of the speaker rather than casting it as an objective fact. Further, the Ilanguage used to initiate a critique was predominately taken up not in a parallel fashion with other I-language, as the literature might predict, but with strong O-sides that flipped or deflected the blame back on the original speaker. It was if the speaker honed in on the hearable critique and, rather than take it in or respond back with their own feelings, the recipient both outright rejected the critique and, more importantly, showed that the original speaker was actually to blame for feeling the way they did. Here, we can see the power of O-sides for not simply managing compliments (see Edwards \& Potter, 2017), but also for deflecting I-language.

Although the S- to O-side oscillation was the most prevalent way that I-language was managed during argumentative exchanges, there were exceptions to this pattern. At times, there was a cascade of consecutive S-sides (I-language) used to both launch and manage critiques. Although both speakers were speaking with almost exclusive I-language, it was uncommon for the speakers to reach agreement or shared perspectives. Instead, the moments where I-language was used consecutively both both speakers often smuggled in the feel of O-side deflections, a finding that goes against the grain of the extant research on the recipocal use of I-language during arguments. It is possible that these were examples where Ilanguage was used almost formulaically or disengenously as a simple token preface to launch what is otherwise a hearable O-side.

At other moments, O-sides dominated the argumentative texture of the interaction. In these examples, the speakers often focused, at least initially, on critiquing an external other. That seemed to create an environment ripe for the omission of I-language, since talking about others is less personal or delicate. This allows the speakers to create a foil for the relational issues, or a contrast by which they can show they have it good by comparison. Though personal critiques do surface in the form of tic-for-tac barbs during these exchanges, they seemed less relationally threatening. In general, O-sides seemed more resistance to deflection and thus less delicate interpersonally. Most importantly, consecutive O-sides are more likely to result in agreement and affiliation by the terminus of the exchange. As noted earlier, it is as if the gossip frame made it easier to both digest and roll with the tic-for-tac barbs and pursue commonality. This finding further undermines the idea that I-language is a most sanguine route for mitigating conflict and pursuing mutual understanding. In these examples, we see how consecutive $\mathrm{O}$-sides create affiliation.

Perhaps the most interesting finding centered on the ways that some types of I-language used S-sides to display a kind of meta-subjective self-awareness of the either the other's potential feelings or an awareness of the intricacies of the relational dynamic itself. There are thus at least two ways to have feelings or thoughts that get articulated in the form of I-language. The first is a more narrow or circumscribed view of one's own feelings/thoughts. The second is a broader more expansive view of one's own feelings about how the other might be feeling or about the workings of the overall relationship in general. It is this second type of perspective that surfaced in some excerpts. Evident in these excerpts is a 
new use of I-language to claim a different kind of subjective stance that is less about one's own perspective and more about an awareness of the other or of both perspectives. The I-language here feels more sophisticated and less solipsistic. It is other-oriented I-language and S-sides that take responsibility (thus inoculating against the need for deflection from the other), and create a space for shared perspective-taking. This often led to alignment as well as affective affiliation. Although far more research is needed on this variety of I-language, it does suggest a sanguine route for the use of Ilanguage. This would radically reshapens the way communication researchers might recommend the use of I-language in conflict. Rather than encourage people to simply express their own feelings, it might be productive to encourage speakers to additionally express how they understand the other's feelings or the overall dynamic in general (a kind of metasubjective focus).

The broad aim of this study is to examine the live interactions of romantic couples in their everyday contexts, with a particular focus on how arguments and conflict is managed interactively. This focus is rare in interpersonal communication research. Further, the use of I-language has a long-standing history that is, currently, increasingly facing scrutiny. This study adds to that realm of inquiry by differentiating the different ways that I-language is actually used by couples, with an emphasis on how various patterns work (or do not work) in mediating conflict. A discursive approach opens us promising opportunities for exploring the mico-analytic interactive processes that couples enage in when negotiating their relationships.

\section{Appendix 1: Transcription Conventions}

(.) Short pause of less than 1 second

(1.5) Timed pause in seconds

[overlap] Overlapping speech

$\uparrow \quad$ Rising intonation

$\downarrow \quad$ Falling intonation

${ }^{\circ}$ quieter ${ }^{\circ}$ Encloses talk that is quieter than the surrounding talk

LOUD Talk that is louder than the surrounding talk

Bold Words emphasized by the transcriber for analytic purposes

Underlined Emphasis

$>$ faster $<$ Encloses talk that is faster than the surrounding talk

<slower> Encloses talk that is slower than the surrounding talk

(brackets) Encloses words the transcriber is unsure about

((comments)) Encloses comments from the transcriber

rea:::ly Elongation of the prior sound

. Stop in intonation

$=\quad$ Immediate latching of successive talk

[...] Where material from the tape has been omitted for reasons of brevity

\section{References}

Argyle, M., \& Furman, A. (1983). Sources of satisfaction and conflict in long-term relationships., Journal of Marriage and the Family, 45, 481-493. https://doi.org/10.2307/351654

Bieson, J. N., Schooler, D. E., \& Smith, D. A. (2016). What a difference a pronoun makes: i/we versus you/me and worried couples' perceptions of their interaction quality. Journal of Language and Social Psychology, 35, 180-205. https://doi.org/10.1177/0261927X15583114

Billig, M. (1987). Arguing and thinking: A rhetorical approach to social psychology. Cambridge: Cambridge University Press.

Bloomquist, M. L. (2012). The practitioner guide to skills training for struggling kids. New York: Guilford Press.

Bruneau, E., \& Saxe, R. (2012). The power of being heard: the benefits of 'perspective-giving' in the context of intergroup conflict. Journal of Experimental Social Psychology, 48, 855-866. https://doi.org/10.1016/j.jesp.2012.02.017

Chiou, W. (2006). Adolescents' sexual self-disclosure on the Internet: Deindividuation and impression management. Adolescence, 41, 547-561. 
Cramer, D. (2001). Destructive disagreement belief, disagreement, negative conflict, and relationship satisfaction in romantic relationships. Genetic, Social, and General Psychology Monographs, 127, 301-317.

Edwards, D. (1994). Script formulations: An analysis of event descriptions in conversation. Journal of Language and Social Psychology, 13, 211-247. https://doi.org/10.1177/0261927X94133001

Edwards, D. (1995). Two to tango: Script formulations, dispositions, and rhetorical symmetry in relationship troubles talk. Research on Language and Social Interaction, 28,319-350. https://doi.org/10.1207/s15327973rlsi2804_1

Edwards, D. (1997). Discourse and cognition. London: Sage.

Edwards, D. (1999). Emotion discourse. Culture \& Psychology, 5, 271-291. https://doi.org/10.1177/1354067X9953001

Edwards, D. (2007). Managing subjectivity in talk. In A. Hepburn \& S. Wiggins (Eds.), Discursive research in practice: New approaches to psychology and interaction (pp. 31-49). Cambridge, UK: Cambridge University Press. https://doi.org/10.1017/CBO9780511611216.002

Edwards, D., \& Potter, J. (1992). Discursive Psychology. Sage: London.

Edwards, D., \& Potter, J. (2017). Some uses of subject-side assessments. Discourse Studies 19, 497-514. https://doi.org/10.1177/1461445617715171

Estrada, M. (2012). Romantic communication in intimate relationships: The romantic construal model. In M.A. Paludi (Ed.), The psychology of love, Vol. I (pp.125-139). Santa Barbara, CA: Praeger.

Gordon, T. (1970). P.E.T., Parent Effectiveness Training: The tested new way to raise responsible children. New York, P.H. Wyden.

Gottman, J. M., \& Levenson, R. W. (2002). A two-factor model for predicting when a couple will divorce: Exploratory analyses using 14-year longitudinal data. Family Process, 41, 83-96. https://doi.org/10.1111/j.15455300.2002.40102000083.x

Hargie, O. (2011). Skilled interpersonal communication. New York: Routledge. https://doi.org/10.4324/9780203833919

Heritage, J., \& Raymond, G. (2005). The terms of agreement: Indexing epistemic authority and subordination in talk-ininteraction. Social Psychology Quarterly, 68, 15-38. https://doi.org/10.1177/019027250506800103

Heydenberk, W., \& Heydenberk, R. (2007). More than manners: conflict resolution in primary level classrooms. Early Childhood Education Journal, 35, 119-126. https://doi.org/10.1007/s10643-007-0185-4

Jacobson, N. S., Follette, W. C., Revenstorf, D., Hahlweg, K., Baucom, D. H., \& Margolin, G. (1984). Variability in outcome and clinical significance of behavioral marital therapy: A reanalysis of outcome data. Journal of Consulting and Clinical Psychology, 52, 497-504. https://doi.org/10.1037/0022-006X.52.4.497

Jefferson, G. (2004). Glossary of transcript symbols with an introduction. In G. Lerner (Ed.), Conversation analysis: Studies from the first generation (pp. 13-31). Amsterdam: John Benjamins. https://doi.org/10.1075/pbns.125.02jef

Kidder, D. L. (2017). BABO negotiating: enhancing students' perspective-taking skills. Negotiation Journal, 33, 255267. https://doi.org/10.1111/nejo.12185

Korobov, N. (2011a). Mate-preference talk in speed-dating conversations. Research on Language and Social Interaction, 44, 166-189. https://doi.org/10.1080/08351813.2011.567102

Korobov, N. (2011b). Gendering desire in speed-dating interactions. Discourse Studies, 13, 461-485. https://doi.org/10.1177/1461445611403357

Korobov, N. (2014). From script theory to script formulation: Derek Edwards' shift from perceptual-realism to the interactional-rhetorical. In C. Tileagă \& E.Stokoe (Eds.), Discursive Psychology: Revisiting classic studies (pp. 210227). London: Sage. https://doi.org/10.4324/9781315863054-12

Korobov, N. (2017). The playful and gendered use of insults and criticisms in romantic couple's everyday banter. Gender and Language, 11, 278-305. https://doi.org/10.1558/genl.26777

Korobov, N. (2018). Indirect pursuits of intimacy in romantic couples everyday conversations: A Discourse analytic approach. Forum Qualitative Sozialforschung / Forum: Qualitative Social Research, 19(2), Art. 21, http://dx.doi.org/10.17169/fqs-19.2.3012.

Korobov, N. (2020). A discursive psychological approach to deflection in romantic couple's everyday arguments. Qualitative Psychology. https://doi.org/10.1037/qup0000161.

Korobov, N., \& Laplante, J. (2013). Using improprieties to pursue intimacy in speed-dating interactions. Studies in Media and Communication, 1, 15-33. https://doi.org/10.11114/smc.v1i1.49 
Kubany, E. S., Bauer, G. B., Muraoka, M. Y., Richard, D. C., \& Read, P. (1995a). Impact of labeled anger and blame in intimate relationships. Journal of Social and Clinical Psychology, 14, 53-60. https://doi.org/10.1521/jscp.1995.14.1.53

Kubany, E. S., Bauer, G. B., Muraoka, M. Y., Richard, D. C., \& Read, P. (1995b). Impact of labeled anger and blame in intimate relationships: Cross-cultural extension of findings. Journal of Cross-Cultural Psychology, 26, 65-83. https://doi.org/10.1177/0022022195261005

Kubany, E. S., Richard, D. C., Bauer, G. B., \& Muraoka, M. Y. (1992). Verbalized anger and accusatory 'you' messages as cues for anger and antagonism among adolescents. Adolescence, 27, 505-516.

Moore, C. W. (2014). The mediation process: Practical strategies for resolving conflict. San Francisco: Jossey-Bass.

Nosko, A., Wood, E., \& Molema, S. (2010). All about me: Disclosure in online social networking profiles: The case of Facebook. Computers in Human Behavior, 26, 406-418. https://doi.org/10.1016/j.chb.2009.11.012

Pomerantz, A. M. (1984). Agreeing and disagreeing with assessments: Some features of preferred/dispreferred turn shapes. In Atkinson JM \& Heritage J (Eds.), Structures of social action: Studies in Conversation Analysis (pp. 57-101). Cambridge: Cambridge University Press. https://doi.org/10.1017/CBO9780511665868.008

Potter, J. (1996). Representing reality. Discourse, rhetoric, and social construction. London: Sage. https://doi.org/10.4135/9781446222119

Potter, J. (2003). Discourse analysis and discursive psychology. In P. M. Camic, J. E., Rhodes \& L. Yardley (Eds.), Qualitative research in psychology: Expanding perspectives in methodology and design (pp. 73-94). Washington: American Psychological Association. https://doi.org/10.1037/10595-005

Rogers, C. R. (1951). Client-centered therapy; its current practice, implications, and theory. Houghton Mifflin.

Rogers, S. L., Howieson, J., \& Neame, C. (2018). I understand you feel that way, but I feel this way: The benefits of Ilanguage and communicating perspective during conflict. PeerJ, 6, e4831. https://doi.org/10.7717/peerj.4831

Ross, L. (1977). The intuitive psychologist and his shortcomings: Distortions in the attribution process. In L. Berkowitz (Ed.), Advances in experimental social psychology, 174-221. New York: Academic Press. https://doi.org/10.1016/S0065-2601(08)60357-3

Simmons, R. A., Gordon, P. C., \& Chambless, D. L. (2005). Pronouns in marital interaction: What do "you" and "I" say about marital health? Psychological Science, 16, 932-936. https://doi.org/10.1111/j.1467-9280.2005.01639.x

Trapp, R., \& Hoff, N. (1985). A model of serial argument in interpersonal relationships. Journal of the American Forensic Association, 22, 1-11. https://doi.org/10.1080/00028533.1985.11951297

Valkenburg, P. M., \& Peter, J. (2009). The effects of instant messaging on the quality of adolescents' existing friendships: A longitudinal study. Journal of Communication, 59, 79-97. https://doi.org/10.1111/j.1460-2466.2008.01405.x

Weisbuch, M., Ivcevic, Z., \& Ambady, N. (2009). On being liked on the web and in the 'real' world: Consistency in first impressions across personal webpages and spontaneous behavior. Journal of Experimental Social Psychology, 45, 573-576. https://doi.org/10.1016/j.jesp.2008.12.009

Whitcomb, C. A., \& Whitcomb, L. E. (2013). Effective interpersonal and team communication skills for engineers. Hoboken: John Wiley \& Sons. https://doi.org/10.1002/9781118514283

Wiggins, S., \& Potter, J. (2003). Attitudes and evaluative practices: Category vs. item and subjective vs. objective constructions in everyday food assessments. British Journal of Social Psychology, 42, 513-531. https://doi.org/10.1348/014466603322595257

Wolfe, J., \& Powell, E. (2009). Biases in interpersonal communication: How engineering students perceive gender typical speech acts in teamwork. Journal of Engineering Education, 98, 5-16. https://doi.org/10.1002/j.21689830.2009.tb01001.x

\section{Copyrights}

Copyright for this article is retained by the author(s), with first publication rights granted to the journal.

This is an open-access article distributed under the terms and conditions of the Creative Commons Attribution license which permits unrestricted use, distribution, and reproduction in any medium, provided the original work is properly cited. 